\title{
Unilateral complete ureteral duplication with distal ureteral stone: A rare entity
}

\author{
Ayhan Karakose, MD; Ozgu Aydogdu, MD; Yusuf Ziya Atesci, MD
}

Izmir University Department of Urology, Izmir, Turkey

Cite as: Can Urol Assoc J 2013;7(7-8):e51 1-2. http://dx.doi.org/10.5489/cuaj.410

Published online on July 2, 2013.

\section{Abstract}

Complete duplex ureters opening separately into the urinary bladder is extremely rare; they can be embryologically explained as a development of two ureteral buds separately from a single mesonephric duct. We describe a case of unilateral complete ureteral duplication with distally localized ureteral stone in a 49-year-old male who presented with right flank pain.

\section{Introduction}

Duplex system can be described as the kidney with two pyelocaliceal systems, with either single ureter or bifid ureter (partial ureteral duplication) or double ureter draining separately into the urinary bladder (complete ureteral duplication). ${ }^{1,2}$ The incidence of duplex renal collecting system and ureter ranges from 0.5 to $3.0 \%{ }^{3,4}$ Complete ureteral duplication is more rarely seen compared to single ureter or partial duplication. ${ }^{3,5}$ Patients with ureteral duplication may potentially have urinary stones, ureterocele, vesicoureteral reflux (VUR) and obstructive uropathy. ${ }^{3,5,6}$

To the best of our knowledge, this the first case report of a patient with unilateral complete ureteral duplication and ureteral stone without coexisting complications, including collecting system obstruction, VUR and/or ureterocele.

\section{Case report}

A 49-year-old male came to the outpatient urology clinic for acute right flank pain. His medical history disclosed no evidence of febrile urinary tract infection, lumber pain or additional urinary problems. His physical examination was normal. Routine laboratory investigations revealed normal findings, except microscopic hematuria in urinalysis. Ultrasound scan showed right renal duplex with minimal dilatation in the lower moiety. Computerized tomography urography revealed a $6.5-\mathrm{mm}$ stone in the distal part of the right ureter which drained the lower moiety of right renal duplex (Fig. 1). Diagnostic cystoscopy showed 2 separate ureteric orifices on the right side of the trigone (Fig. 2). Ureteroscopy revealed the ureteral stone in the distal part of the ureter localized on the lateral side of the bladder (Fig. 3). Stone disintegration was performed using high power holmium:yttrium aluminum garnet laser. The stone fragments were retrieved using foreign body forceps and $4.8 \mathrm{~F}$ ureteral stent was placed in the ureter via ureteroscope. The postoperative period was uneventful and the patient was discharged on the postoperative first day.

\section{Discussion}

Throughout the embryonic development, 2 ureteral buds rarely develop separately from a single mesonephric duct, giving rise to a duplex kidney with ureteral duplication., ${ }^{2,5}$ Unilateral complete ureteral duplication with a single renal parenchyma drained by 2 pyelocaliceal systems is even more rare. ${ }^{2}$ Urinary stone formation is a possible comorbidity which can be observed in patients with duplex system. ${ }^{2,5}$ Few reports include patients with duplex systems and urinary stones with coexisting ureterocele and/or collecting system obstruction. ${ }^{2,3,5}$ To the best of our knowledge, this is the first case with unilateral complete ureteral duplication and ureteral stone without coexisting comorbidities including VUR, ureterocele and obstructive uropathy.

The orifice draining the lower moiety of renal duplex open superior and lateral to the orifice draining the upper moiety in most cases, as in our patient. ${ }^{2}$ In a duplex kidney drained by double ureter, the lower moiety is more frequently affected compared to the upper pole due to coexisting complications since the lower moiety is dominant in most patients with renal duplex. ${ }^{2,5}$ This was the case in our patient.

Although we successfully managed the patient and retrieved the ureteral stone without any complications, several complications may occur due to complete ureteral 


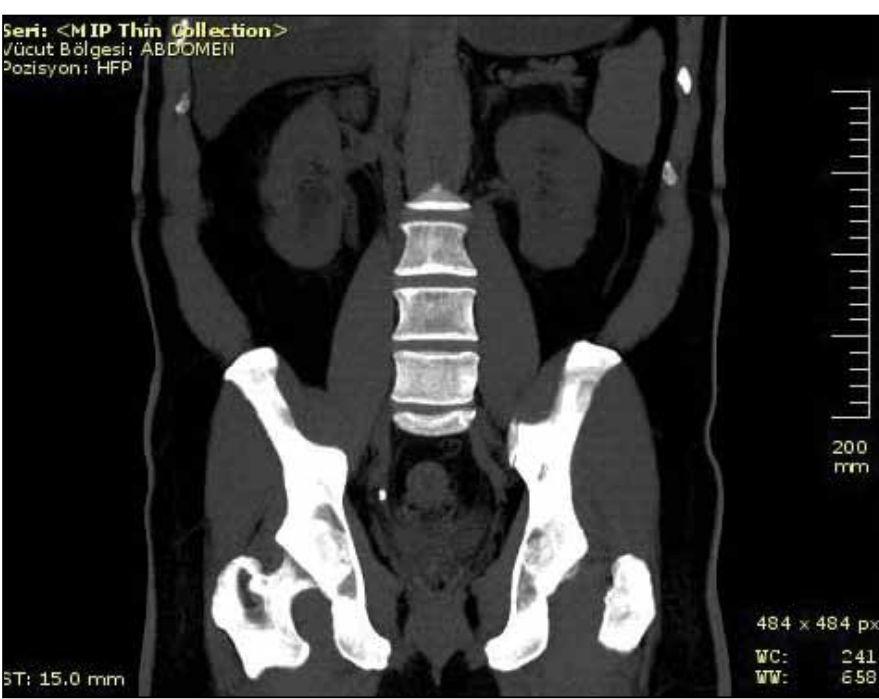

Fig. 1. Computerized tomography urography (in non-contrast series) revealed a $6.5-\mathrm{mm}$ stone in the distal part of the right ureter which drains the lower moiety of right renal duplex.

duplication. ${ }^{2}$ The use of high power holmium:yttrium aluminum garnet laser may be more safe compared to pneumatic lithoclast for the disintegration of ureteral stones in patients with coexisting urinary anomalies.

\section{Conclusion}

Clinicians should be cautious about anomalies of the urinary system previous to the surgical management of urinary stones, since coexisting anomalies, including complete ureteral duplication, may increase the morbidity of affected individuals.

Competing interests: None declared.

This paper has been peer-reviewed.

\section{References}

1. Dalla PL, BAzzocchi M, Cressa C, et al. Radiological anatomy of the kidney revisited. Br J Radiol 1990;63:680-90. http://dx.doi.org/10.1259/0007-1285-63-753-680

2. Prakash, Rajini T, Venkatiah J, et al. Double ureter and duplex system: a cadaver and radiological study. Urol J 201 1;8:145-8.

3. Kawahara $\mathrm{T}$, Ito $\mathrm{H}$, Terao $\mathrm{H}$, et al. Ureteroscopy assited retrograde nephrostomy (UARN) for an incomplete double ureter. Urol Res 2012;40:781-2. http://dx.doi.org/10.1007/s00240-012-0486-y

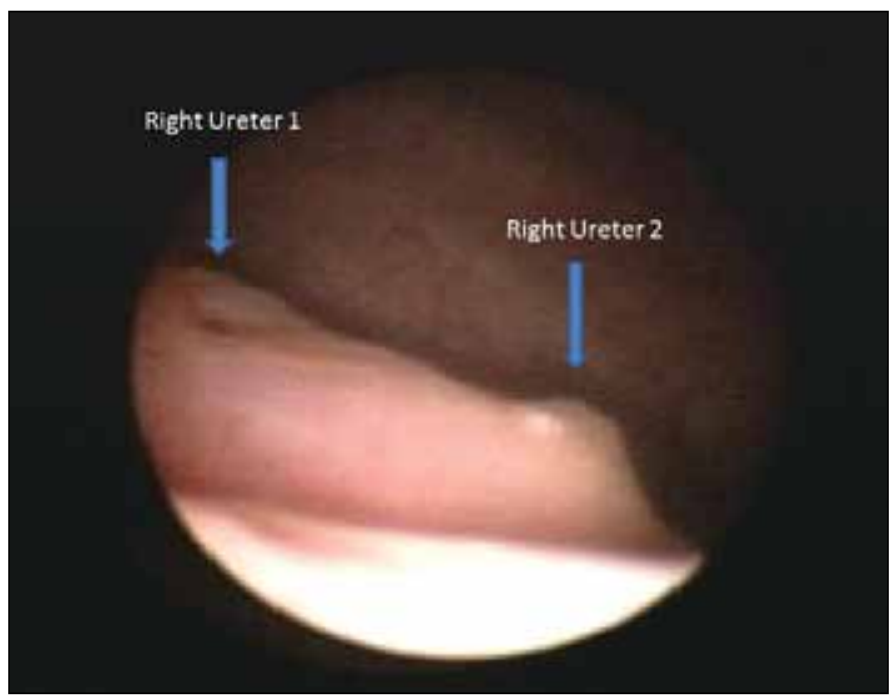

Fig. 2. Diagnostic cystoscopy showed 2 separate ureteric orifices on the right side of the trigone.

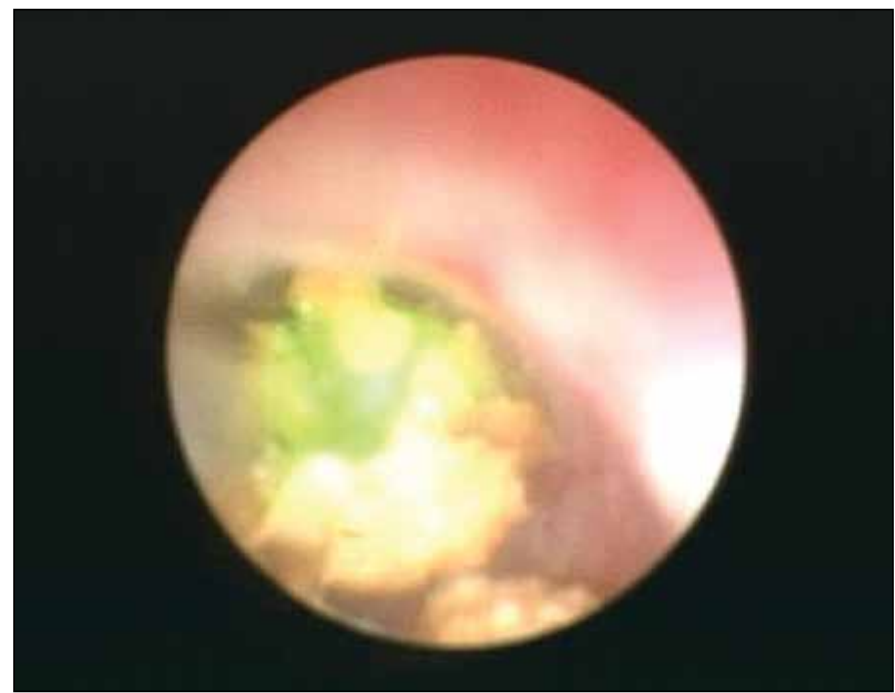

Fig. 3. Ureteroscopy revealed the ureteral stone in the distal part of the ureter.

4. Inamoto K, Tanaka S, Takemura K, et al. Duplication of the renal pelvis and ureter: associated anomalies and pathological conditions. Radiat Med 1983;1:55-64.

5. Ghobashy A, El-Shazly M, Lari A, et al. A case of complete renal duplex with H-shaped ureter. Case Reports Urol 2012. http://dx.doi.org/10.1155/2012/643207

6. Dominici A, Travaglini F, Maleci $M$, et al. Giant stone in a complete duplex ureter with ureterocele. A case report. Urol Int 2003;71:336-7. http://dx.doi.org/10.1159/000072691

Correspondence: Dr. Ozgu Aydogdu, Medical Park Izmir Hospital Department of Urology, Karsiyaka, Izmir, Turkey; ozgucan@yahoo.com 